\title{
O FESTIVAL DE CINEMA PACHAMAMA E A CONDIÇÃO COLONIAL DO AUDIOVISUAL NO ACRE
}

\section{THE PACHAMAMA FILM FESTIVAL AND THE COLONIAL CONDITION OF THE AUDIOVISUAL PRODUCTION IN ACRE}

\author{
João José Veras de Souza ${ }^{1}$
}

\begin{abstract}
Tenho como de grande importância $\quad$ o $\quad$ Festival
\end{abstract} Pachamama para o cinema latino americano,como um evento que difunde o ver e promove o pensar a partir das audiovisualidades, as que nos fazem refletir sobre a nossa condição geocultural e que coloca o audiovisual como parte de um processo político e estético muito além de um mero produto de consumo/entretenimento. Este é um aspecto desse evento que carrega outros não tão expressos, mas igualmente pertinentes para a cultura acreana. Pretendo aqui pensar a respeito.

O Pachamama, todavia, com essa ampla relevância, não passa, frente à cena cultural mesmo latina, de uma isla pequenita afastada em um lugar distante e sem tradição na cinematografia do continente. Isla-evento para a qual alguns poucos - muitos poucos - visitam/frequentam anualmente procurando acessar películas contemporâneas que estão fora do esquadro da indústria mundial do cinema. Para aonde outros buscam reconhecimento/troféu/título/ currículo, aprendizagem, troca, trabalho, grana, ocupar tempo, amizade, paquera, diversão, aprendizagem, entretenimento... Alguns - da reduzida e passageira elite local - se limitam a cumprir a nobre missão social de abrir e fechar a grande festa de abertura do evento, quando o foco público, mesmo reduzido, é maior, coisa de poucos socialites e autoridades constituídas da aldeia. Imaginam (é o que imagino): é fashion, é de vanguarda, talvez popular... Os demais dessas turmas, nem isso, passam ao largo. Vade-retro, devem pensar.

Não por falta de divulgação, o público escasso é quase sempre

${ }^{1}$ Doutor em Ciências Humanas pelo Programa de Pós-Graduação Interdisciplinar em Ciências Humanas pela Universidade Federal de Santa Catarina (2016), músico, poeta e advogado. Este ensaio, inédito, foi escrito em 12 de julho de 2017. 
o mesmo. 0 Festival se esforça em não passar em branco para a plateia e sai tentando se espraiar pela cidade. Muitas sessões e debates são salvos (sobretudo em quantidade) por professores e seus alunos espantados com o que não é Hollywood. Motivos todos legítimos! Ninguém é obrigado a gostar (nem entender) de cinema, muito menos daquele tipo - tão estranho à massa - celebrado pelo festival. A escola não cumpre seu papel de democratizar e descolonizar a cultura visual. 0 resultado disso é a produção de seres humanos monovisuais. Findo o evento, quase todos retornam à sua rotina cômoda de consumir o mesmo em seus cubos privados e telas de shoppings centers. Ano que vem a ilhazinha aportará de novo no estranho continente imagético do ver universal. Massa!

Insisto na imagem da ilha para pensar a relação do festival com a realidade local. Interessame aqui tratar do que nos afeta, da influência e importância para nosotros que ficamos depois da badalada Pachafesta, que acontece no último dia do evento. 0 que faço não só como contraponto para o não local, para los otros. Não que o evento deva ser responsabilizado pela política audiovisual desde aqui. Trata-se de pensar com ele, a partir dele e além dele. Com ele em si, sinto uma sugestão de que estamos bem nesta área - além dele - apesar de se tratar de um evento de iniciativa privada, como todo aquele dependente de verba estatal com a qual é possível a sua realização e sem a qual vira tãosomente mais uma lembrança do que um dia aconteceu nesta terra do "já teve”. É necessário ter muito claro os seus caracteres, de índoles precárias, tanto temporário quanto de dependência - dois dos seus limites que lhes dão sobrevida por um fio. 0 fio do poder local.

Há sete anos que o festival é realizado em Rio Branco. E tem acontecido sempre com apoio dos poderes governamentais locais. Todavia, estes mesmos poderes, especialmente da área cultural, jamais ofereceram qualquer política de Estado voltada para o estímulo e apoio à produção videográfica e cinematográfica da região. Se este apoio ao festival - que é muito pequeno (tendo em vista que o evento tem sido sustentado basicamente por verba federal) - é, para os governos 
locais, as suas parcelas de apoio ao audiovisual da terra, então reafirmo que continuamos sem política para a área, inclusive de perfis democrático/participativo, haja vista que, até para este parco apoio, o movimento local do audiovisual - não necessariamente organizado - não é consultado, não participa, não decide.

Noutro aspecto, reduzir uma política de audiovisual apenas ao intercâmbio (dado como um dos fortes objetivos do festival vinculado ao apoio oficial "Cinema de fronteira", este é o seu lema) não basta, sobretudo esta espécie de intercâmbio em que a reciprocidade não funciona, tendo em vista que sugestiona - senão patenteia - um "lugar de fora" a partir do qual o conhecimento esperto advém. Em regra, quem julga, quem palestra, quem ensina e quem faz o filme é "de fora", o que coloca o de "dentro" na outra ponta "oca” da condição de saber e poder. A velha métrica colonial a impor hierarquias e ignorar alteridades.

O fato dessa efetivaausência de política cultural para o audiovisual local reflete diretamente na própria programação do festival que, a cada ano, tem dificuldade de atender à necessária (imagino) cota de filmes acreanos. Nem pensar incluí-los no rol das obras competitivas. Nestes sete anos tal fenômeno nunca aconteceu. Não somente pela noção de qualidade que os festivais mundo afora impõem - o que é seguido pelo Pachamama - mas por falta mesmo de obras. E porque falta qualidade e porque não tem obra? Penso que é fundamental buscar respostas para estas perguntas.

A propósito, no último dia do festival, numa tarde quente de sábado, "foram rodados" três filmes - Ausências e Passagens, de Danilo de S'acre; Cadeia Velha, de Messias Nunes, e Seu Hélio, de Juca Badaró - os quais estavam fora da competição e qualificados na programação como parte da Mostra Amazônia (a parte que nos cabe, guetizada no regionalismo). Os três foram feitos no Acre e sobre o Acre. Nenhum teve qualquer apoio dos poderes públicos nem locais nem federal. Um deles faz questão de dizer isto, com todas as letras, nos créditos de sua abertura. Os demais, não foi preciso. 0 que demonstra também que, apesar da ausência 
do Estado, como fomentador da expressão audiovisual e garantidor do constitucional direito cultural, a produção resiste. Fossem produzidos com melhores condições (estrutura, equipamento...), o que significa com verba suficiente para suportar os desejos criativos, tais obras estariam - como possibilidade real - não na programação de mostras regionalizadas, em uma tarde quente de sábado, mas, na competição e para além das fronteiras locais. Quem sabe assim, para o cinema latino, esta fronteira distante não seria tão distante, o evento não seria tão ilha, a produção local não seria tão reduzida ao local.

Em alguma das edições do festival, as condições locais de produção de vídeo e cinema foram de fato debatidas em sua programação oficial. Nessa oportunidade, sei que o "pessoal do audiovisual" reclamou política pública para a aérea. Lembro que foi realizado um evento especial a respeito, inclusive com a chancela estatal. Apareceu até uma associação nacional de vídeo com representação local. Mas nada foi feito. E tudo se aquietou. Talvez o debate tivesse no fundo tal intento. Coisa de doido, parece, mas não é - passa por estratégias oficiais de desmonte de mobilização social para o seu controle. Assim tem sido a lógica da "democracia" local.

E o Pachamama - essa é a minha impressão - deixou de tocar nesse assunto, pelo menos de forma direta, objetiva, enfática. A sensação que tenho é que as discussões de seu interesse estão voltadas ou para questões técnicas ou para os temas - no campo da política - que o cinema latino americano trata - vale dizer, tudo que se faz fora daqui. Sobre a política cultural local, nada. $\mathrm{Na}$ verdade, outra intuição que tenho é que, o "pessoal do audiovisual" daqui "não gosta muito" de produzir algo que trate - de forma crítica - dos poderes constituídos locais. Há um déficit estrondoso de produção audiovisual sobre o poder local, este espectro imune de visualidades críticas. E olha que só estou me referindo às questões em torno da política cultural do audiovisual! Eu compreendo as razões. Não vivemos ainda em plena liberdade de pensamento e criação. Especialmente se essa liberdade pretender ser exercida 
com dinheiro público. Havendo o mínimo de indícios de crítica, a resposta é enfática: no hay dinero. A falta de política para o audiovisual funciona como um eficiente atalho impeditivo para quem pretende produzir algo que não ignore a realidade social e as forças políticas que a mantém. Quem vive aqui sabe como funciona o "nosso" regime democrático. Penso que realizar um filme a tal respeito nos colocaria na tradição da crítica de um certo cinema latino, certamente. Enredos temos de sobra.

Nesta edição do Festival, a Secretaria de Estado de Comunicação e a Fundação Aldeia - e não a Fundação Estadual de Cultura Elias Mansour - foram homenageadas. Ambos os fatos significativos. A justificativa da homenagem consta da matéria jornalística produzida pela agência de notícias do governo: "Como forma de reconhecimento pelo apoio [ao Festival] ao longo das sete edições". Em síntese, pela divulgação do evento. Legítimo o reconhecimento. É claro que a divulgação é importante. Mas, para os interesses locais, sem obra para que serve a divulgação? Para o festival só a divulgação do evento basta? E os filmes, por que não constam da programação da emissora? Nesse sentido, penso que o festival (não necessariamente a sua organização, mas especialmente a cena que alberga), pelo seu caráter, poderia - senão deveria - se comprometer, neste exato aspecto, de forma explícita e concreta, com os interesses da produção local, o que faria não exatamente celebrando quem muito pouco faz pela produção, mas questionando a ausência de política pública para o audiovisual local. É de conhecimento público que a TV Aldeia há tempos que não produz nada. Nem programa de entrevistas com os políticos alinhados. Não preciso nem falar no que diz respeito ao apoio à produção do audiovisual local. Infelizmente, o sistema de comunicação do Estado - especialmente pelo meio televisivo - tem se reduzido à difusão diária de dois produtos: um pequeno telejornal de caráter oficial (divulga os feitos administrativos do governo) e a retransmissão da programação do sudeste. Agora não estou a tratar de uma impressão, mas de um 
fato. Devemos agradecer por isto? Porém, o Festival de cinema o faz com ênfase!

Desejo que o Pachamama, como um dos importantes difusores do cinema latino americano contemporâneo, tenha efetivamente uma razão local de existir (em torno de uma produção audiovisual a partir do olhar daqui) e não se acomode no papel de um tipo de hospedeiro e difusor da audivisualidade externa (com as suas qualidades e importâncias), de uma espécie de capa que tem contribuído para acobertar, de alguma forma, o violento déficit de política cultural local no campo do audiovisual e, assim, como um núcleo "inocente" de reforço da condição colonial no campo da cultura.

Não merecemos viver somente para expectar/reproduzir o que vem "de fora" (mesmo que este "de fora" não venha da Hollywood colonizadora), tampouco silenciar frente a uma forma velada de política estatal de censura ao audiovisual (especialmente em sua potência de criticidade). Será que a condição colonial contra a qual, em regra, o cinema latino americano se debate historicamente - ainda permanece e se fortalece justamente no contexto do evento que se propõe a homenagear a resistência? Que "martírio"2 é esse, Acre?

${ }^{2}$ Referência ao filme vencedor desta edição do festival, Martírio, de Vicent Carelli. 